\title{
Comparison of Performance and Operation of Side-By-Side Integrated Fixed-Film and Conventional Activated Sludge Processes at Demonstration Scale
}

\author{
Anne-Emmanuelle Stricker ${ }^{1}$, Ashley Barrie ${ }^{2}$, Carol L. A. Maas ${ }^{3}$, \\ William Fernandes ${ }^{2}$, Lori Lishman ${ }^{1 *}$
}

\begin{abstract}
A full-scale demonstration of an integrated fixed-film activated sludge (IFFAS) process with floating carriers has been conducted in Ontario, Canada, since August 2003. In this study, data collected on-site from July 2005 to December 2006 are analyzed and compared with the performance of a conventional activated sludge train operated in parallel. Both trains received similar loadings and maintained comparable mixed liquor concentrations; however, the IFFAS had 50\% more biomass when the attached growth was considered.

In the winter, the conventional train operated at the critical solids retention time (SRT) and had fluctuating partial nitrification. The IFFAS nitrified more consistently and had a doubled average capacity. In the summer, the suspended SRT was less limiting, and the benefit of IFFAS for nitrification was marginal.

The lessons learned from the operational requirements and challenges of the IFFAS process (air flow, carrier management, and seasonal foaming) are discussed, and design recommendations are proposed for whole plant retrofit. Water Environ. Res., 81, 219 (2009).
\end{abstract}

KEYWORDS: integrated fixed-film activated sludge, conventional activated sludge, floating biofilm carriers, nitrification, solids retention time, operation, airflow, foaming.

doi: $10.2175 / 106143008 \times 325692$

\section{Introduction}

The integrated fixed-film activated sludge (IFFAS) process using floating plastic carriers is one possible way of achieving year-round nitrification without major capital expansion. The addition of carriers to the aeration tank allows the process to operate at much longer solids retention times (SRTs) without increasing the mixed liquor suspended solids (MLSS) concentration. The Region of Peel in Ontario, Canada, has been operating an IFFAS process as a fullscale demonstration project at the Lakeview Wastewater Treatment Plant (WWTP) since August 2003. Their objective is to assess the suitability of this technology, in terms of performance and operation, for plantwide implementation. Currently, the plant is

\footnotetext{
${ }^{1}$ Environment Canada, Water Science and Technology Directorate, Burlington, Ontario, Canada.

${ }^{2}$ Region of Peel, Brampton, Ontario, Canada.

${ }^{3}$ Hydroxyl Systems Inc., Victoria, British Columbia, Canada.

* Environment Canada, Water Science and Technology Directorate, 867 Lakeshore Road, P.O. Box 5050, Burlington, ON, L7R 4A6, Canada; e-mail: Lori.Lishman@ec.gc.ca.
}

required to partially nitrify in the summer $(17 \mathrm{mg}-\mathrm{N} / \mathrm{L}$ monthly average); however, the Region is proactively exploring options to enhance the removal of ammonia, because it is listed as a priority substance under the Canadian Environmental Protection Act.

This demonstration study is novel for two reasons. First, the IFFAS train was operated in parallel with a conventional activated sludge (CAS) train of comparable design. This approach differs from that of most field studies, where data collected before and after the IFFAS implementation are compared. Before modifications necessary for the IFFAS trial, the two trains were identical and interconnected through their return activated sludge lines. The connections were eliminated, because they are a limitation to conducting a valid process comparison (Hubbell et al., 2006; Yerrell et al., 2001). During the study, the operators strived to operate both trains identically, in terms of loading and suspended biomass concentration, so the performance of the two processes could be compared directly.

Second, this study is one of only two full-scale IFFAS projects in North America using floating plastic carriers. The other case study is in Broomfield, Colorado (Johnson and Haegh, 2005; Onnis-Hayden et al., 2007; Rutt et al., 2006). Other full-scale studies with similar IFFAS carriers examined plants that were either much smaller (Jones et al., 1999) or located outside North America (Yerrell et al., 2001). The remaining North American IFFAS case studies deal with different media, such as floating sponges (Federico et al., 2002; Masterson et al., 2004) or fixed media (Hubbell et al., 2006; Psaltakis et al., 2003).

This paper examines data collected by Lakeview plant staff from July 2005 to December 2006, when operations were fairly stable. Advanced data analysis was performed to evaluate the IFFAS train against the reference train for overall performance, seasonal variations, and operational aspects. Earlier results (October 2003 to May 2004) have been published by Ross et al. (2004). The interim period (June 2004 to June 2005) was not evaluated, because the loading fluctuated widely, as a result of intermittent sidestream returns from the biosolids treatment process (BTP).

\section{Materials and Methods}

An overview chart presenting the structure and the steps of the study is shown in Figure 1.

Description of the Demonstration Trains. The Lakeview WWTP is located in a growing urban area on the shore of Lake 
Table 1-Characteristics of the IFFAS train.

\begin{tabular}{lll}
\hline $\begin{array}{l}\text { Suspended growth section } \\
\text { Total volume }\end{array}$ & & \\
Anoxic fraction & $\mathrm{m}^{3}$ & 1152 \\
Anoxic volume & $\%$ & $25 \%$ \\
Hybrid growth section & $\mathrm{m}^{3}$ & 288 \\
Total volume & & \\
Number of cells & $\mathrm{m}^{3}$ & 2304 \\
Carrier fill fraction & - & 4 \\
Protected surface area & $\%(\mathrm{v} / \mathrm{v})$ & $46 \%$ \\
Specific surface area & $\mathrm{m}^{2}$ & 425316 \\
Overall fractions & $\mathrm{m}^{2} / \mathrm{m}^{3}$ tank & 185 \\
Suspended anoxic section & & $8 \%$ \\
Suspended aerobic section & $\%$ & $25 \%$ \\
Hybrid aerobic section & $\%$ & $67 \%$ \\
\hline
\end{tabular}

Ontario. The facility consists of three conventional activated sludge plants (named plants 1 to 3 ), resulting from successive expansions, and had a total capacity of $448000 \mathrm{~m}^{3} / \mathrm{d}$ by 2006 . Sidestreams from the BTP are returned to the primary clarifiers. The biosolids treatment underwent major process modification during the 20042006 period (Ross and Fernandes, 2002). The resulting changes in sidestreams affected primary effluent strength and composition during the demonstration study.

The demonstration project was implemented in two trains of plant 1 , which collectively treat approximately $6 \%$ of Lakeview WWTP's total flow. They share a common primary clarifier, but are otherwise independent from each other and from other trains. The CAS train has retained its original design (Figure 2), consisting of a 3-pass plug-flow tank (PFT) of $3456 \mathrm{~m}^{3}$, equipped with fine-bubble tapered aeration. Ferrous chloride for phosphorus co-precipitation is injected at the head of pass 2. Final separation is achieved by a rectangular clarifier $\left(493 \mathrm{~m}^{2}\right)$, designed for a surface loading rate (SLR) of $175 \mathrm{~kg} /\left(\mathrm{m}^{2} \cdot \mathrm{d}\right)$ at peak flow.

The IFFAS demonstration train has undergone both process and mechanical changes in support of carrier addition (Figure 2). An anoxic selector was set up at the head of pass 1 , because it was anticipated that filamentous growth would occur as a consequence of higher sludge ages (Table 1). ActiveCell450 carriers provided by Hydroxyl Systems Inc. (Victoria, British Columbia) were added at a $46 \%$ fill ratio (v/v) to passes 2 and 3 . The polyethylene pieces have a wagon-wheel shape (21-mm diameter and 16-mm length) and a reported inner protected surface area of $402 \mathrm{~m}^{2} / \mathrm{m}^{3}$. Carriers in passes 2 and 3 provide a protected surface area of $185 \mathrm{~m}^{2} / \mathrm{m}^{3}$ of tank volume. For carrier containment, each pass was subdivided into 2 cells, and the downstream end of each of the 4 cells was equipped with a vertical flat screen and a coarse bubble airknife. For process aeration, the fine-bubble diffusion system was preserved; however, the average diffuser density was doubled from 8.5 to $16.8 \%$. Additional air was needed for carrier mixing and to maintain higher dissolved oxygen concentrations $(>4 \mathrm{mg} / \mathrm{L})$ to counteract the diffusion resistance of the biofilm.

Data Collection. Monitoring Period. Operational data presented in this paper was collected between July 1, 2005, and December 31, 2006. Supplementary studies were conducted between February and April 2007 to fill gaps identified in the 2005-2006 data set (Stricker et al., in press). Measurements included concentration profiles across the tanks and additional suspended and attached biomass characterization (e.g., total Kjeldahl nitrogen [TKN]/chemical oxygen demand [COD], iron/ total suspended solids [TSS]). Some of the information collected was used to refine calculations in the 2005-2006 data set.

Flow Measurements. Daily total flows of final effluent, waste activated sludge (WAS) and return activated sludge (RAS) were recorded. Instantaneous readings of airflows were taken daily off the plant's supervisory control system. The total flow of iron chloride $\left(\mathrm{FeCl}_{2}\right)$ was not available for each train, but was calculated as a fraction of the total volume of the chemical used for the whole plant. It was assumed that both trains receive a constant and equal fraction of the ferrous chloride flow.

Influent and Effluent Sampling. Time composite samples (24hour) of primary and final effluent were collected by refrigerated autosamplers (Figure 2). Total ammonia-nitrogen $\left(\mathrm{NH}_{4}-\mathrm{N}\right)$ was analyzed on-site using Hach kits (Hach Company, Loveland, Colorado) 5 times per week. All other parameters (TSS, volatile suspended solids [VSS], 5-day biochemical oxygen demand $\left[\mathrm{BOD}_{5}\right]$, filtered $\mathrm{BOD}_{5}, \mathrm{COD}, \mathrm{TKN}, \mathrm{NO}_{2}-\mathrm{N}, \mathrm{NO}_{3}-\mathrm{N}$, and alkalinity) were analyzed according to Standard Methods (APHA et al., 2005) by a commercial laboratory between 1 and 3 times a week.

Monitoring of the Biological Stage. The TSS was analyzed daily on-site in grab samples of mixed liquor collected at the end of pass 3 and on the clarifier underflow. Instant readings of dissolved oxygen and temperature in the mixed liquor were taken daily at the end of pass 3 with a handheld probe.

Table 2-Cumulative frequency distribution of influent loadings to both trains.

\begin{tabular}{|c|c|c|c|c|c|c|c|c|c|c|}
\hline & & & \multicolumn{2}{|c|}{ Design } & \multicolumn{5}{|c|}{ Percentile } & \multirow{2}{*}{$\begin{array}{l}\text { \# Data } \\
\text { points (-) }\end{array}$} \\
\hline & & & Value & Cum. freq. & $5 \%$ & $25 \%$ & $50 \%$ & $75 \%$ & $95 \%$ & \\
\hline \multirow[t]{2}{*}{ Flow } & \multirow[t]{2}{*}{$\mathrm{m}^{3} / \mathrm{d}$} & CAS & 14000 & $85 \%$ & 8230 & 9870 & 11400 & 12900 & 16200 & 488 \\
\hline & & IFFAS & 14000 & $87 \%$ & 7200 & 9600 & 11300 & 13200 & 14900 & 494 \\
\hline \multirow[t]{2}{*}{ TSS } & \multirow[t]{2}{*}{$\mathrm{kg} / \mathrm{d}$} & CAS & 1720 & $37 \%$ & 1060 & 1490 & 2090 & 3140 & 6100 & 133 \\
\hline & & IFFAS & 1720 & $35 \%$ & 854 & 1430 & 2050 & 2980 & 6120 & 135 \\
\hline \multirow[t]{2}{*}{$\mathrm{BOD}_{5}$} & \multirow[t]{2}{*}{$\mathrm{kg} / \mathrm{d}$} & CAS & 2240 & $50 \%$ & 1090 & 1600 & 2300 & 3760 & 4990 & 133 \\
\hline & & IFFAS & 2240 & $45 \%$ & 900 & 1600 & 2360 & 3510 & 5020 & 136 \\
\hline \multirow[t]{2}{*}{ TKN } & \multirow[t]{2}{*}{$\mathrm{kgN} / \mathrm{d}$} & CAS & 644 & $64 \%$ & 247 & 332 & 496 & 725 & 1010 & 133 \\
\hline & & IFFAS & 644 & $67 \%$ & 232 & 341 & 506 & 706 & 931 & 136 \\
\hline \multirow[t]{2}{*}{ Alkalinity } & \multirow[t]{2}{*}{$\mathrm{kgCaCO}_{3} / \mathrm{d}$} & CAS & - & - & 2170 & 2430 & 2890 & 3430 & 4200 & 47 \\
\hline & & IFFAS & - & - & 1450 & 2530 & 2960 & 3520 & 4120 & 47 \\
\hline
\end{tabular}


Table 3-Cumulative frequency distribution of operational parameters of both trains.

\begin{tabular}{|c|c|c|c|c|c|c|c|c|c|c|}
\hline & & & \multicolumn{2}{|c|}{ Objective } & \multicolumn{5}{|c|}{ Percentile } & $\begin{array}{l}\text { \# Data } \\
\text { points (-) }\end{array}$ \\
\hline & & IFFAS susp. & & & 1620 & 2160 & 2640 & 3230 & 4120 & 495 \\
\hline & & IFFAS total ${ }^{a}$ & & & 3280 & 4010 & 4600 & 5190 & 6380 & 231 \\
\hline $\begin{array}{l}\text { Mixed liquor } \\
\text { VSS:TSS }\end{array}$ & & CAS & - & - & 0.61 & 0.69 & 0.73 & 0.78 & 0.84 & 49 \\
\hline \multirow{2}{*}{ Dynamic SRT } & & IFFAS susp. & & & 2.3 & 3.1 & 3.7 & 4.6 & 5.8 & 490 \\
\hline & & IFFAS total & & & 3.8 & 5.0 & 5.9 & 6.9 & 8.4 & 490 \\
\hline \multirow[t]{3}{*}{$\mathrm{F} / \mathrm{Mv}$} & $\begin{array}{l}\mathrm{kgBOD}_{5} / \\
(\mathrm{kgMLVSS} \cdot \mathrm{d})\end{array}$ & CAS & 0.25 & $21 \%$ & 0.17 & 0.26 & 0.37 & 0.52 & 0.80 & 131 \\
\hline & & IFFAS susp. & 0.25 & $20 \%$ & 0.16 & 0.29 & 0.39 & 0.49 & 0.70 & 134 \\
\hline & & IFFAS total ${ }^{\mathrm{b}}$ & 0.25 & $52 \%$ & 0.11 & 0.18 & 0.24 & 0.32 & 0.46 & 134 \\
\hline \multirow{2}{*}{$\begin{array}{l}\text { Dissolved oxygen } \\
\text { end of pass } 3\end{array}$} & $\mathrm{mg} / \mathrm{L}$ & CAS & - & - & 2.4 & 4.1 & 5.2 & 6.4 & 7.7 & 485 \\
\hline & & IFFAS & & & 4.8 & 6.0 & 7.0 & 8.0 & 8.7 & 487 \\
\hline \multirow{2}{*}{$\begin{array}{l}\text { Final clarifier } \\
\text { SLR }\end{array}$} & $\mathrm{kg} /\left(\mathrm{m}^{2} \cdot \mathrm{d}\right)$ & CAS & 175 & $96 \%$ & 56 & 79 & 100 & 128 & 170 & 473 \\
\hline & & IFFAS & 175 & $90 \%$ & 64 & 92 & 116 & 147 & 196 & 474 \\
\hline \multirow{2}{*}{$\begin{array}{l}\text { RAS/WAS } \\
\text { TSS conc. }\end{array}$} & $\mathrm{mg} / \mathrm{L}$ & CAS & - & - & 2680 & 4560 & 5950 & 7430 & 9790 & 488 \\
\hline & & IFFAS & & & 2240 & 3890 & 5230 & 6810 & 9170 & 495 \\
\hline
\end{tabular}

a Equivalent TSS concentration in passes 2 and 3 only, not in the whole IFFAS train.

b VSS was not measured on the carriers. The total F/Mv calculation assumes the same volatile fraction for attached and suspended biomass.

c Temperature was only measured in the IFFAS train and assumed to be the same in the CAS train.

The attached biomass on the IFFAS carriers (expressed in grams total solids per square meter) was measured twice per month on a grab sample in cells $2 \mathrm{a}$ and $3 \mathrm{~b}$. The total solids analysis was performed on-site following the method described in Maas et al. (2006).

Data Analysis. Data Quality Assessment. Primary effluent analytical data were evaluated by examining concentration ratios (e.g., VSS/TSS, COD/TKN). Only $0.8 \%$ of the values were identified as inconsistent and eliminated, thereby indicating a good quality data set. Mass balances for TSS, total nitrogen (TN), and COD were verified using average mass flows. The average mass flows for influent, effluent, and sludge streams were calculated after removing the 5\% lowest and 5\% highest values from the data set to exclude operational upsets and peak events. The mass balance closure on TSS fell outside the range considered as acceptable (85 to $115 \%$ ). The measured sludge production (WAS + effluent solids) did not match the sludge production rate predicted with a formula that considers the solids generation from $\mathrm{BOD}_{5}$ removal and the accumulation of organic and inorganic inerts from influent and from iron precipitation (Grulois et al., 1996). The WAS flowrate measurements were considered to be suspect, in part, because plants 1 and 2 have common wastage lines. When performing the TSS mass balance on clarifiers alone, more than one-third of the solids inputs

Table 4-Cumulative frequency distribution of final effluent concentrations of both trains.

\begin{tabular}{|c|c|c|c|c|c|c|c|c|c|c|}
\hline & & & \multicolumn{2}{|c|}{ Limit } & \multicolumn{5}{|c|}{ Percentile } & \multirow{2}{*}{$\begin{array}{l}\text { \# Data } \\
\text { points (- }\end{array}$} \\
\hline & & & Value & Cum. freq. & $5 \%$ & $25 \%$ & $50 \%$ & $75 \%$ & $95 \%$ & \\
\hline \multirow[t]{2}{*}{ TSS } & \multirow[t]{2}{*}{$\mathrm{mg} / \mathrm{L}$} & CAS & 15 & $90 \%$ & 1 & 4 & 7 & 10 & 22 & 243 \\
\hline & & IFFAS & 15 & $91 \%$ & 1 & 3 & 5 & 9 & 20 & 250 \\
\hline \multirow[t]{2}{*}{ COD } & \multirow[t]{2}{*}{$\mathrm{mg} / \mathrm{L}$} & CAS & - & - & 28 & 37 & 55 & 73 & 86 & 50 \\
\hline & & IFFAS & - & - & 25 & 34 & 55 & 67 & 85 &, 52 \\
\hline \multirow[t]{2}{*}{$\mathrm{CBOD}_{5}$} & \multirow[t]{2}{*}{$\mathrm{mg} / \mathrm{L}$} & CAS & 15 & $100 \%$ & $<2$ & $<2$ & 4 & 6 & 7 & 50 \\
\hline & & IFFAS & 15 & $98 \%$ & $<2$ & $<2$ & $<2$ & 4 & 8 & 51 \\
\hline \multirow[t]{2}{*}{$\mathrm{NH}_{4}-\mathrm{N}$} & \multirow[t]{2}{*}{$\mathrm{mgN} / \mathrm{L}$} & CAS & $5^{a}$ & $32 \%$ & 0.1 & 2.4 & 11.0 & 21.0 & 28.4 & 273 \\
\hline & & IFFAS & $5^{a}$ & $58 \%$ & $<0.1$ & 0.5 & 3.5 & 9.0 & 18.6 & 280 \\
\hline \multirow[t]{2}{*}{$\mathrm{NO}_{2}-\mathrm{N}+\mathrm{NO}_{3}-\mathrm{N}$} & \multirow[t]{2}{*}{$\mathrm{mgN} / \mathrm{L}$} & CAS & - & - & 2 & 4 & 9 & 16 & 22 & 50 \\
\hline & & IFFAS & & - & 9 & 13 & 15 & 17 & 23 & 52 \\
\hline \multirow[t]{2}{*}{ Alkalinity } & \multirow[t]{2}{*}{$\mathrm{mgCaCO}_{3} / \mathrm{L}$} & CAS & - & - & 25 & 63 & 113 & 181 & 216 & 49 \\
\hline & & IFFAS & - & - & 24 & 51 & 74 & 94 & 141 & 51 \\
\hline
\end{tabular}




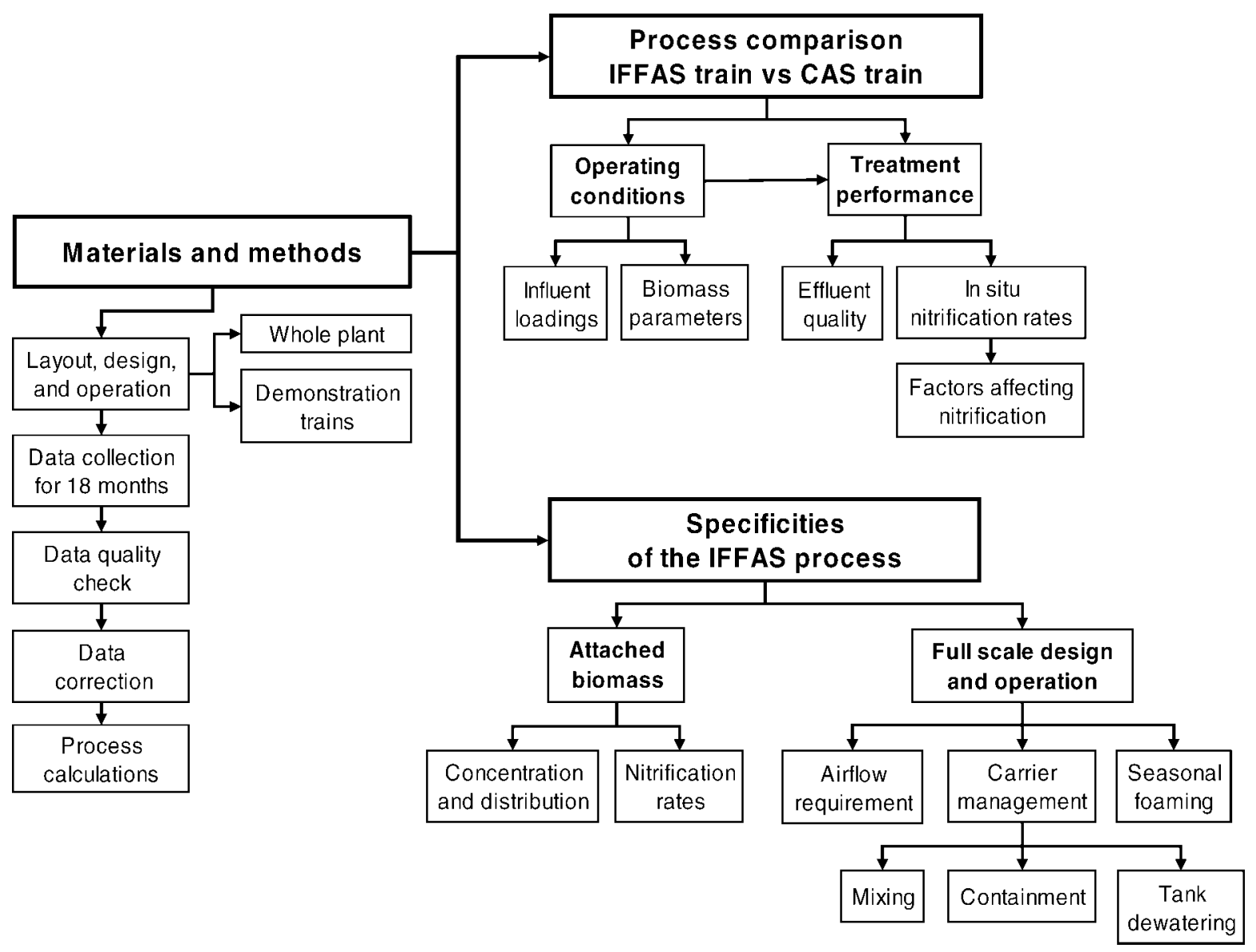

Figure 1-Overview of the structure of the study.

were missing in the measured outputs. This outcome, with other considerations, led us to suspect that the RAS flowrates were underestimated by a factor of 2.0 (CAS) to 2.6 (IFFAS).

Because wastage and recycle flowrates are significant variables in further process calculations, data reconciliation was required. The WAS flowrate data were replaced with the calculated daily sludge production rates, and the RAS flowrates were back-calculated, assuming that the mass balance on the clarifiers were closing at $100 \%$.

Nitrogen and COD mass balances, calculated with the method from Barker and Dold (1995), were within the acceptable range. They became closer to $100 \%$ when corrected sludge production and recycle flowrates were used in place of original values, which indirectly validates the corrections.

Calculation of Operational and Kinetic Parameters. Only nonstandard calculations are outlined here.

The traditional SRT calculation using daily wastage rates was not appropriate in this study because of the error in wastage flowrates. The dynamic SRT (dSRT) concept (Takacs and Patry, 2004) was used instead. It calculates the mean age of the particle population, by performing an age balance considering previously existing sludge and newly generated sludge. The dynamic SRT has the following advantages when compared with the traditional SRT:

(1) The calculation uses sludge production (calculated) and sludge masses (measured) data, rather than wastage data; and

(2) It delivers a closer estimation of the "true" age of the biomass and a smoother trend.
The theoretical SRT causing nitrifier washout (critical SRT, in days) was calculated according to eq 1 (Metcalf and Eddy, 2003):

$$
S R T_{\text {crit }}(T)=\frac{1}{\mu_{A}\left(T, D O, N H_{4}\right)-b_{A}(T)}
$$

Where

$$
\begin{aligned}
T= & \text { activated sludge temperature }\left({ }^{\circ} \mathrm{C}\right) ; \\
\mu_{\mathrm{A}}= & \text { in situ nitrifier growth rate }\left(\text { day }^{-1}\right) \text { corrected for } \\
& \text { temperature, oxygen, and ammonia concentra- } \\
& \text { tion; and } \\
b_{\mathrm{A}}= & \text { nitrifier decay rate }\left(\mathrm{day}^{-1}\right) \text { corrected for temper- } \\
& \text { ature. }
\end{aligned}
$$

The default values for $\mu_{\mathrm{A}}, b_{\mathrm{A}}$, and the temperature correction coefficients are those proposed by Dold et al. (2002). The ammonia concentration was set at the effluent objective for the demonstration train $(5 \mathrm{mg} \mathrm{N} / \mathrm{L})$. The dissolved oxygen concentration takes into account the non-aerated sludge fractions and the average dissolved oxygen in aerated sections.

The nitrification rates, $F_{\mathrm{Nit}}(\mathrm{kg}-\mathrm{N} / \mathrm{d})$, were calculated based on an ideal TKN mass balance. This approach was preferred to the method using the effluent nitrite + nitrate $(\mathrm{NOx}-\mathrm{N})$ concentrations, because

(1) $\mathrm{NO}_{\mathrm{x}}-\mathrm{N}$ measurements were infrequent (51 values versus 136 for TKN); and 

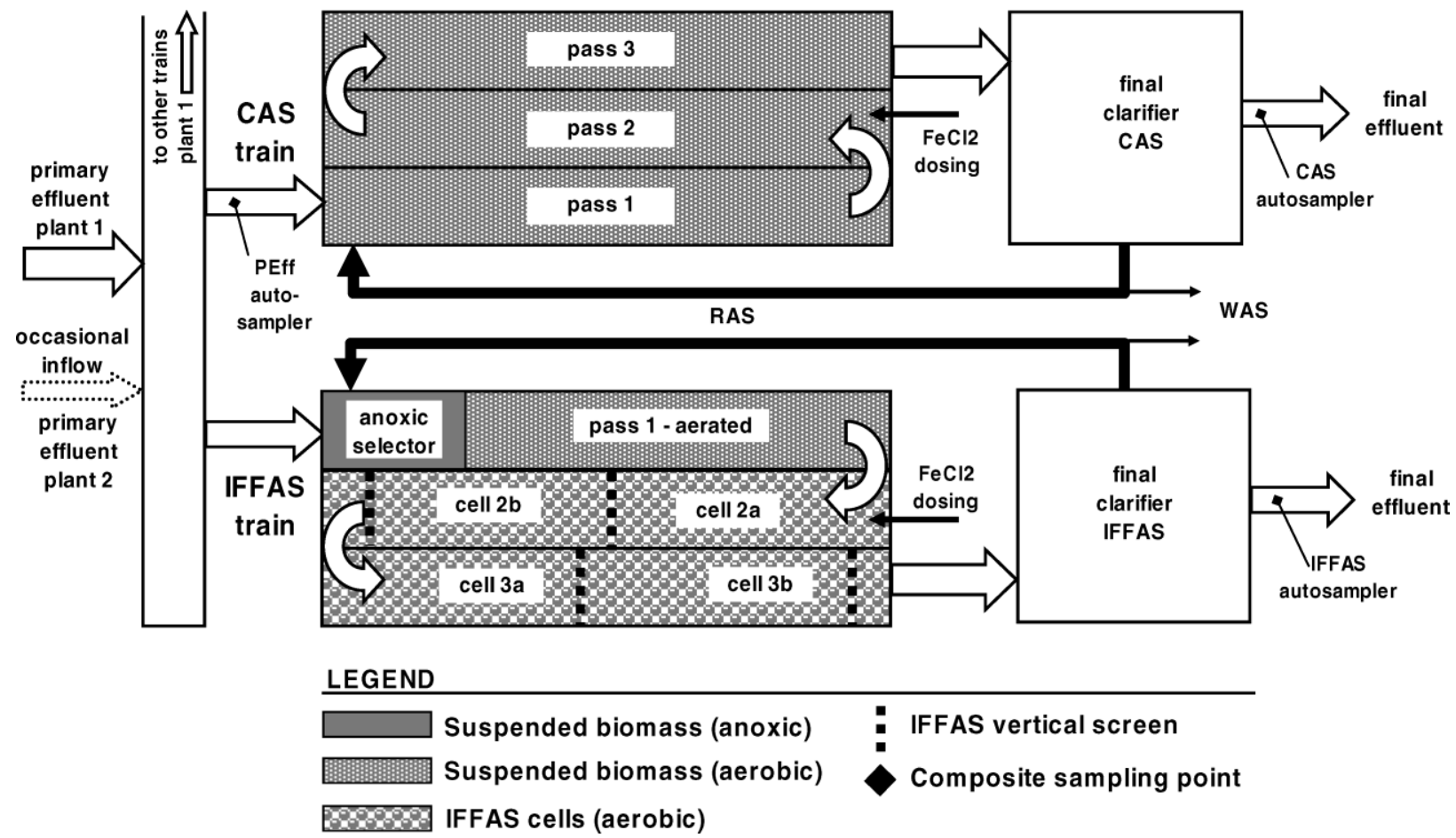

Figure 2-Layout of the demonstration trains.

(2) It was impossible to quantify nitrogen losses resulting from denitrification in the final clarifiers, or even in the aerated portion of the tanks, in case simultaneous nitrificationdenitrification (SND) was occurring (Rutt et al., 2006).

The data collected here do not permit direct calculation of separate nitrification rates for the attached and suspended biomasses. However, specific rates for the attached biomass were approximated using assumptions found in Sen et al. (2005); the carriers contribute $80 \%$ of the total nitrification when the suspended SRT is equal to or below the critical value; otherwise, both biomasses contribute equally (50\%).

Data Presentation. Because raw data points were numerous and scattered, the following two types of illustrations were designed to compare the operation and performance of the demonstration trains with improved legibility and enhanced trends:

(1) Cumulative distribution frequencies are summarized in Tables 2 to 5 by five percentiles and by the cumulative frequency at the design or objective value. Significant differences between the two trains are highlighted in bold.

(2) For time plots, data was smoothed using 15-day moving averages. Absolute values are shown for the CAS reference train, while the IFFAS train is represented by differences only.

\section{Comparison of Process Performance}

Operating Conditions. Loadings. The $\mathrm{BOD}_{5}$ loading of the CAS train exceeded its design capacity of $2240 \mathrm{~kg} / \mathrm{d}$ for $50 \%$ of the time (Table 2). The following two main periods can be seen in Figure 3:

(1) From July 2005 to January 2006, the CAS train was consistently overloaded-by $80 \%$, on average. This resulted from the hydraulic loading being at or above the design capacity, combined with high-strength sidestreams.
(2) From February to December 2006, the loading dramatically dropped and remained close to design levels, except for two peak periods in April and November 2006. To reduce the loading, the feed flow was gradually decreased through the first half of 2006, and the solids-rich BTP sidestream was eliminated in February. After that date, high loadings still occurred, either when the sludge blankets of the primary clarifiers were carried over, or when higher strength primary effluent from plant 2 inflowed to plant 1 (Figure 2).

The TKN loading correlates with the $\mathrm{BOD}_{5}$ loading; however, the extent and frequency of nitrogen overloading were lower, because the actual TKN:BOD 5 ratio of the influent (median 0.21 ) was lower than the design value $(0.29)$. The nitrogen design capacity of $644 \mathrm{~kg}-\mathrm{N} / \mathrm{d}$ was exceeded $36 \%$ of the time (Table 2). During the period of chronic overloading (July 2005 to January 2006), the average nitrogen loading exceeded design by $25 \%$.

Because the IFFAS and the CAS trains were fed with a common primary effluent, loading differences (Figure 3 and Table 2) are a consequence of uneven flow distribution. Flows to both trains were equal most of the time, except for July to September 2005 (the IFFAS received a lower flow) and August to November 2006 (the IFFAS received a higher flow).

Biomass Parameters. The MLSS in the CAS train varied between 1600 and $3900 \mathrm{mg} / \mathrm{L}$, with a median value of $2540 \mathrm{mg} / \mathrm{L}$ (Table 3 ). The total mass of solids in the aeration basin and clarifier was $10000 \mathrm{~kg}$ (median value). The MLSS concentration in the IFFAS train was comparable with the values in the CAS train, except in August 2005 and November 2006, when there were long-term loading differences (Figure 3). The IFFAS train had $5200 \mathrm{~kg}$ of attached biomass (median value), representing a supplement of $51 \%$ to the suspended mass.

The volatile fraction of the mixed liquor (Table 3) was low (median 0.73 ), mainly as a result of iron dosing. Similar VSS-to- 


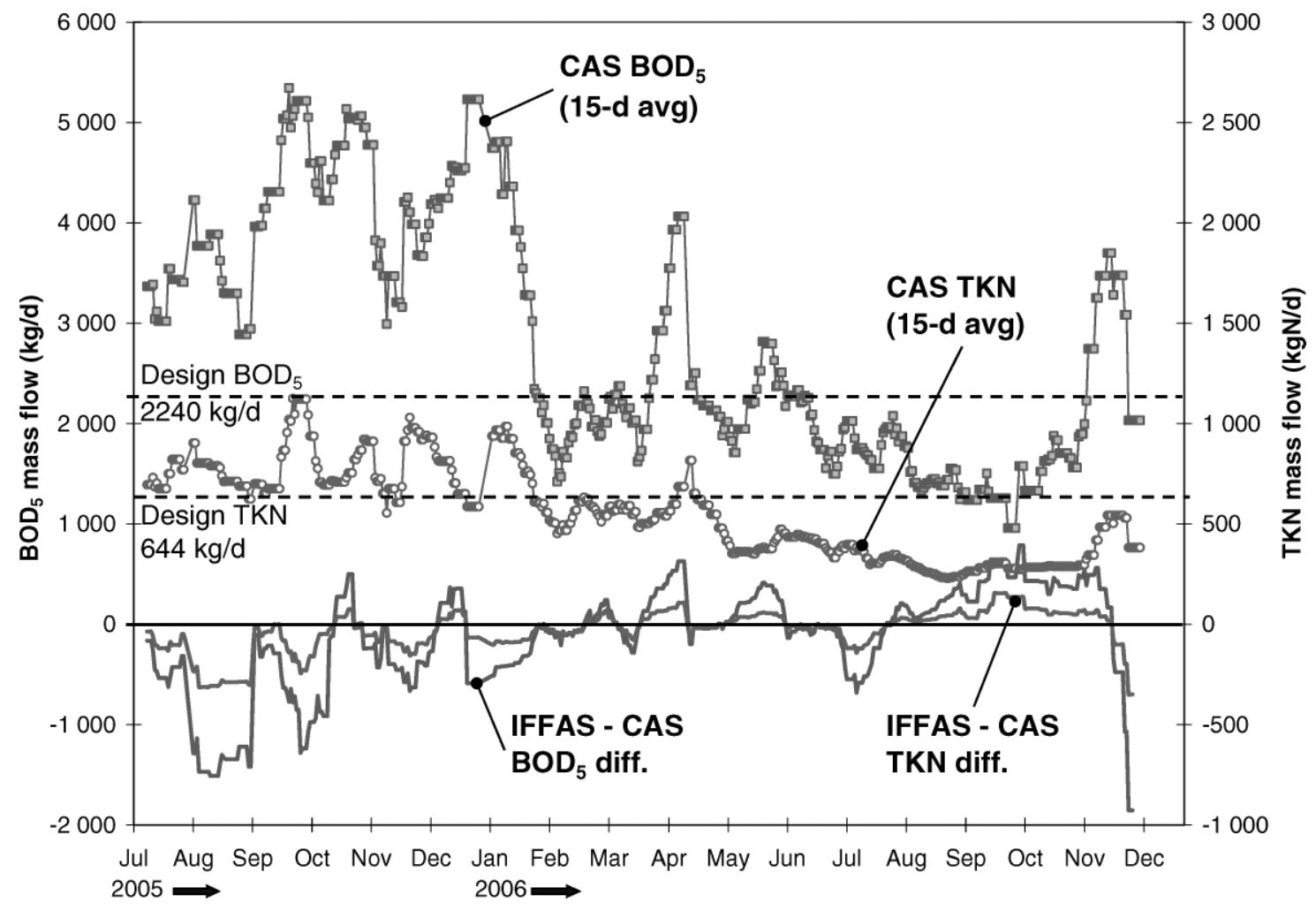

Figure 3- $\mathrm{BOD}_{5}$ and TKN influent loading to the CAS train (15-day averages of absolute values) and to the IFFAS train (as difference with the CAS train).

TSS ratios in both trains suggest that they received comparable iron doses.

Because both trains received similar loadings and operated at similar MLSS concentrations, their suspended dSRTs were equivalent (Table 3), with a median value of approximately 3.6 days. If the attached biomass is also considered, the median total dSRT of the IFFAS train was 5.9 days. However, this combined value is a misrepresentation, because the true age of the suspended biomass is shorter, and the true age of the biofilm is much longer.

The food-to-microorganism ratio was calculated with respect to the mass of volatile solids and noted $\mathrm{F}: \mathrm{M}_{\mathrm{v}}$ (Table 3). If mixed liquor is considered only, both trains were operating at the higher end of the conventional activated sludge range $\left(0.2\right.$ to $0.4 \mathrm{~kg}-\mathrm{BOD}_{5} / \mathrm{kg}-$ MLVSS $\cdot d$, Metcalf and Eddy, 2003). The design objective of 0.25 $\mathrm{kg}-\mathrm{BOD}_{5} / \mathrm{kg}-\mathrm{MLVSS} \cdot \mathrm{d}$ was exceeded for $80 \%$ of the time. When the attached biomass is taken into consideration also, the IFFAS train operated near the lower end of the conventional range. Its median $\mathrm{F}: \mathrm{M}_{\mathrm{v}}$ ratio matched the design objective, meaning that it was still exceeded for half the time, which occurred mostly in 2005.

The temperature in the activated sludge basin (Table 3) appears rather warm in the Canadian context. The coldest temperatures, encountered from February to mid-April, were approximately $15^{\circ} \mathrm{C}$. Lakeview is located in Southern Ontario, where winters are mild. In addition, the characteristics of the collection system (short retention time and low proportion of runoff) limit the influence of climatic factors, such as air and ground temperature or snowmelt episodes.

In summary, the IFFAS and the CAS train were operated under similar conditions regarding hydraulic, organic, and nitrogen loadings, and for all parameters related to the suspended biomass. This is a significant achievement for full-scale operation and allows unbiased comparison of the two processes. Because of the attached biomass supplement, the IFFAS train had a lower $\mathrm{F}: \mathrm{M}_{\mathrm{v}}$ and higher total dSRT.

Effluent Quality. The effluent concentrations are compared in Table 4

Organic and Solids Concentrations. The CAS train typically had efficient clarification, as shown by the low effluent TSS concentrations. The clarifier was operating below its design SLR most of the time, and the plug-flow configuration and the iron dosing may have contributed to good sludge settleability. Despite being overloaded during the first 6 months, the train always met the $\mathrm{BOD}_{5}$ limit of $15 \mathrm{mg} / \mathrm{L}$ (Table 4).

The IFFAS train had slightly lower solids effluent concentration than the CAS train. The significance of the 1- to 2-mg/L difference can be questioned, given the analytical precision of TSS, but it seems confirmed by the slightly lower COD and $\mathrm{BOD}_{5}$ concentrations. This is remarkable, because the IFFAS clarifier was operating under higher SLRs $(+15 \%$, Table 3$)$. The reason was a higher recycling ratio (median 0.92) than for the CAS (median 0.70 ), based on corrected RAS flows, which translates into lower RAS solids concentration (Table 3). The reasons may include a better sludge flocculation or compaction than in the CAS, as observed in other studies (McQuarrie et al., 2004; Psaltakis et al., 2003; Von Munch et al., 2000), or differences in clarifier operation.

Nitrogen Concentrations. The CAS train had poor and unstable nitrification performance. Its median ammonia effluent concentration was $11 \mathrm{mg} / \mathrm{L}$, and it only met the objective of $5 \mathrm{mg}-\mathrm{N} / \mathrm{L}$ for $32 \%$ of the time (Table 4). For the period February to December 2006, when TKN loading was below the design limit for $90 \%$ of the time, the ammonia compliance rate rose to $47 \%$. 


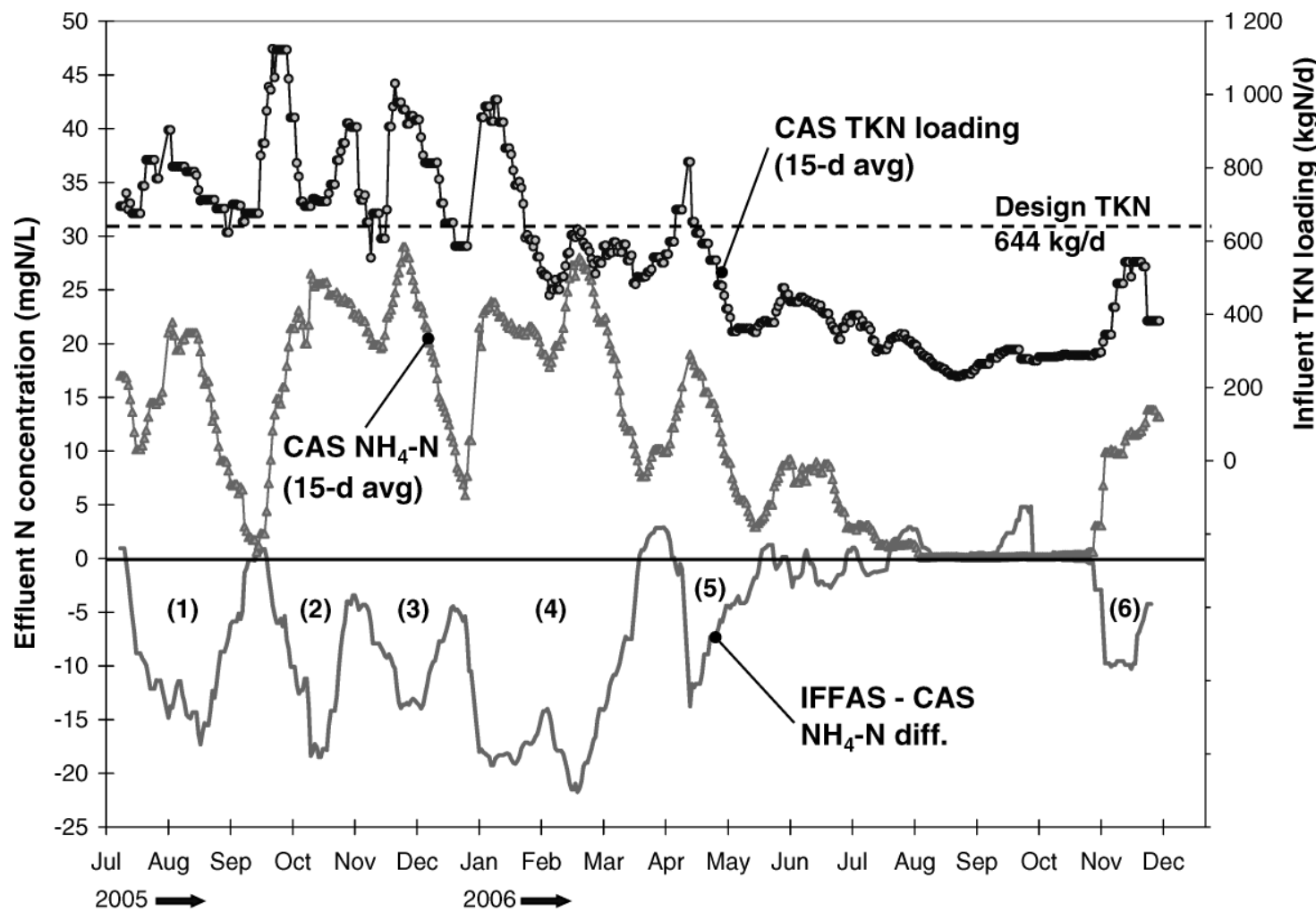

(\#) refer to periods when the IFFAS discharge levels were lower than the CAS.

Figure 4-Effluent $\mathrm{NH}_{4}-\mathrm{N}$ concentrations of the CAS train (15-day averages of absolute values) and of the IFFAS train (as difference with the CAS train).

The time plot reveals that the CAS effluent ammonia concentrations followed the TKN load variations (Figure 4). When the plant was chronically overloaded in 2005 , the CAS train was not able to fully process the incoming TKN load, except when complete nitrification was established during the first half of September 2005. The effluent quality deteriorated soon again for the whole winter, even once loading rates started to decrease from February 2006. Complete nitrification established again from the end of July 2006, once temperatures climbed above $22^{\circ} \mathrm{C}$ and TKN loadings were stable and low ( 240 to $300 \mathrm{~kg}-\mathrm{N} / \mathrm{d}$ ).

The IFFAS train had improved ammonia removal compared with the CAS train, with a median of $3.5 \mathrm{mg}-\mathrm{N} / \mathrm{L}$. It met the objective of $5 \mathrm{mg}-\mathrm{N} / \mathrm{L}$ for $58 \%$ of the time (Table 4 ). For the 9 -month period with reduced TKN loading, the compliance rate increased to $67 \%$.

There are six periods identified on Figure 4 when the effluent of the IFFAS train had lower $\mathrm{NH}_{4}-\mathrm{N}$ levels than the CAS train. For period 1 , the cause is operational, because the IFFAS train was receiving lower influent loadings (Figure 3). During periods 2 to 5 , both trains received more similar loading, so it can be inferred that the IFFAS had an enhanced nitrification performance during the cold period. The interruption between periods 4 and 5 is the result of a slight overload on the IFFAS train. Both trains had identical ammonia removal from June to October 2006, when temperatures were high and the TKN loadings were both low and stable. Differences emerged again in November 2006. The IFFAS train maintained complete nitrification for at least 3 more weeks after the CAS train stopped nitrifying (6). Monitoring was interrupted at this point, so the cold weather performance cannot be confirmed during the winter of 2006 to 2007.

The NOx-N concentrations in the CAS effluent varied between 2 and $22 \mathrm{mg}-\mathrm{N} / \mathrm{L}$ (Table 4) and were inversely correlated with the effluent ammonia. Denitrification is a marginal process on this train, because it may only occur in the clarifier. The IFFAS train discharged more NOx-N than the CAS train, as a consequence of better nitrification. However, they both discharged the same amount of total inorganic nitrogen $\left(\mathrm{TiN}=\mathrm{NOx}-\mathrm{N}+\mathrm{NH}_{4}-\mathrm{N}\right)$. The absence of additional nitrogen loss in the IFFAS train suggests that it did not denitrify any more than the CAS train, despite the presence of the anoxic selector. This would also rule out the possibility of SND. The high dissolved oxygen concentrations measured at the end of pass 3 (Table 3 ) confirm that denitrification in the biofilm was unlikely in cell $3 \mathrm{~b}$. However, the dissolved oxygen concentration in the other 3 cells was lower, according to dissolved oxygen profiles measured during the supplementary winter study in winter 2007 (Stricker et al., in press). These data show that the dissolved oxygen concentration increased almost linearly along the IFFAS section, with a difference of 2 to $3 \mathrm{mg} / \mathrm{L}$ between the first and last cell. If this observation is extended to the 2005-2006 data set, a dissolved oxygen concentration of $6 \mathrm{mg} / \mathrm{L}$ in cell $3 \mathrm{~b}$ ( $25 \%$ percentile) would translate into a dissolved oxygen concentration of 3 to $4 \mathrm{mg} / \mathrm{L}$ in cell $2 \mathrm{a}$. Below $4 \mathrm{mg} / \mathrm{L}$, the oxygen penetration depth in the biofilm might be limited. As a consequence, conditions for denitrification in the biofilm might have been met for approximately $25 \%$ of the time in the first IFFAS cell, where there 


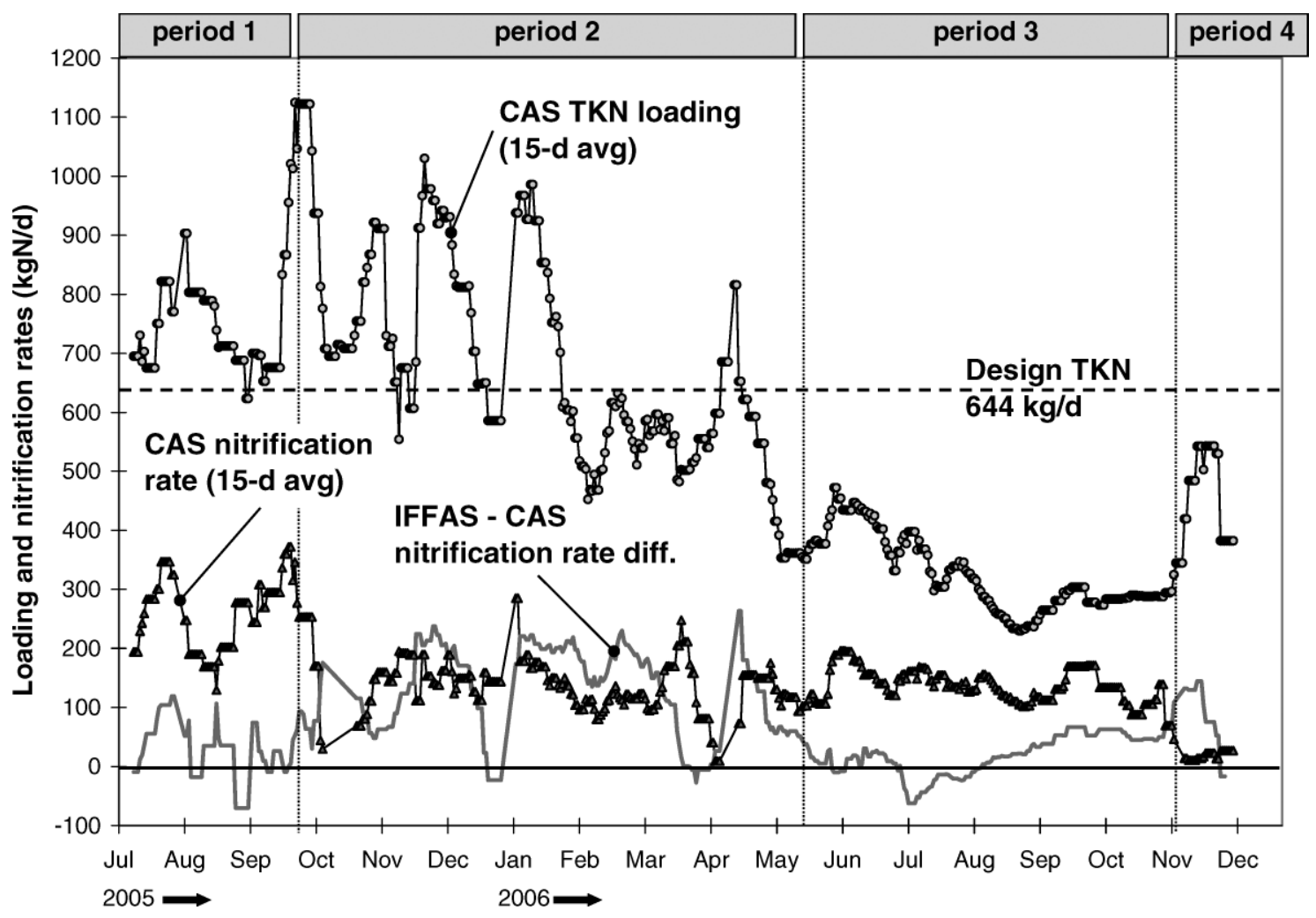

Figure 5-Calculated in situ nitrification rates for the CAS train (15-day averages of absolute values) and for the IFFAS train (as difference with the CAS train).

is a favorable combination of lower dissolved oxygen with higher COD concentrations and biofilm thickness. However, these conditions would limit nitrification in the first cell (Sen et al., 2005); thus, the denitrification was limited by NOx-N substrate. Therefore, some denitrification by the carriers cannot be completely excluded, but it was probably a marginal phenomenon, in terms of frequency and intensity. This may be why there is no evidence of SND in the limited NOx-N data available.

In conclusion, the effluent nitrogen concentrations confirm that the IFFAS train had an improved ammonia removal performance compared with the reference train, but it did not achieve complete year-round nitrification during the study. The IFFAS train did not appear to have any significant benefit for denitrification; however, this conclusion relies on a limited TiN data set (47 values) and calls for more investigations.

Nitrification Capacity. Nitrification rates are better comparison criteria than effluent nitrogen concentrations, because they represent in situ treatment capacity and are less influenced by shortterm TKN loading variations or imbalances between trains. The rates calculated from TKN mass balances for both trains are presented in Figure 5. When the effluent ammonia concentration was $>1 \mathrm{mg} / \mathrm{L}$, the rates represent the maximum nitrification capacity under the physical-chemical conditions in the tank. Otherwise, the rates were substrate-limited, which was the case between July and October 2006.

Figure 5 shows that the CAS train was partially nitrifying most of the time. Nitrification rates ranged between 0 and $324 \mathrm{~kg}-\mathrm{N} / \mathrm{d}$, with a median of $134 \mathrm{~kg}-\mathrm{N} / \mathrm{d}$. Nitrification contributed less to ammonia removal than nitrogen assimilation into the sludge (median value $187 \mathrm{~kg}-\mathrm{N} / \mathrm{d}$ ). The remaining reduced nitrogen was discharged under soluble form with the effluent (median value 136 $\mathrm{kg}-\mathrm{N} / \mathrm{d}$ ).

During periods 1 and 3, the dSRT was always above the critical value by 1.0 to 3.5 days (Figure 6). Consequently, a stable autotrophic population was established, but it was only able to oxidize part of the applied loading. In the fall and early winter (period 2a), the dSRT was only slightly above the critical value. This explains the sudden drop in nitrification rates and the increase in effluent ammonia concentrations (Figure 4). During the second part of the winter (period 2b), the actual dSRT fluctuated around the critical value. Averaged calculated nitrification rates were still approximately $100 \mathrm{~kg}-\mathrm{N} / \mathrm{d}$, but individual values (not shown) fluctuated between 0 and $200 \mathrm{~kg}-\mathrm{N} / \mathrm{d}$ for this period. Nitrification was able to resume each time the dSRT stayed above the critical value for a few days, but the population was easily washed out again.

Two periods of prolonged loss of nitrification occurred in late March and early November 2006. They can both be correlated to $\mathrm{BOD}_{5}$ loading peaks (Figure 3), which may cause a sudden drop in dSRT (e.g., early November on Figure 6) and reduced dissolved oxygen concentrations.

In the summer (periods 1 and 3), the nitrogen load nitrified by the IFFAS train was equal to or slightly higher than that nitrified by the CAS train. In the winter (periods 2 and 4), the IFFAS train nitrified 50 to $150 \%$ more load than the control train. The loss of nitrification by the IFFAS train at the end of November 2006 was the result of an intentional wastage of a fraction of the mixed liquor to facilitate emergency repair work. 


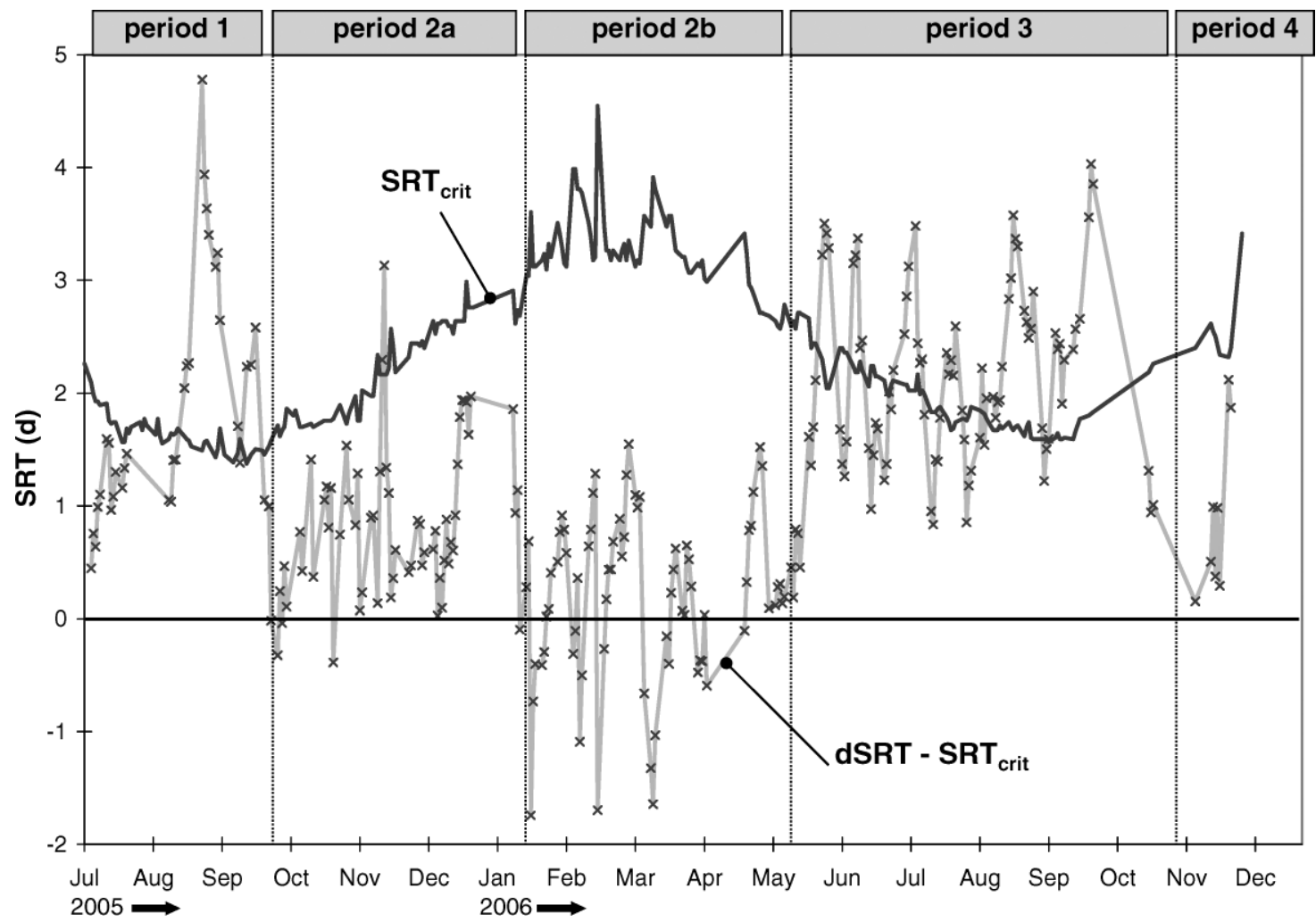

Figure 6-Difference between the actual dynamic SRT and the critical SRT for nitrifiers in the CAS train.

The total dSRT of the IFFAS train was always above the critical value-by 4.5 days, on average (not shown). This may suggest that, in the absence of TKN overload (starting in January 2006), the IFFAS train should have achieved complete nitrification. Possible limiting factors include the following:

(1) Dissolved oxygen. It was incorporated to eq 1 using the default half-saturation coefficient for suspended nitrifiers $(0.4 \mathrm{mg} / \mathrm{L})$. The appropriate value for attached biomass might be 10 times as high because of stronger diffusion resistance through the biofilm. As discussed earlier, dissolved oxygen might have been limiting for nitrification in cell $2 \mathrm{a}$ up to $25 \%$ of the time. This emphasizes the importance of maintaining high dissolved oxygen levels across the whole IFFAS section and at all times. It advocates for careful aeration design accounting for peak loading and for control and flexibility in airflow distribution.

(2) Alkalinity. The final concentration in the IFFAS train was lower than the recommended residual of 70 to $80 \mathrm{mg}-\mathrm{CaCO}_{3} / \mathrm{L}$ (Metcalf and Eddy, 2003) for approximately 50\% of the time (Table 4). This indicates that alkalinity is probably another limiting factor for the nitrification in the IFFAS train, which was not incorporated to eq 1 . This plant is at risk for alkalinity limitations, because it combines several alkalinity-consuming processes (ferrous chloride dosage and nitrification), and recovery through denitrification is marginal. $\mathrm{pH}$ was not measured in regular operation, but its daily monitoring would help to detect alkalinity limitations and take corrective actions where possible.

Given these limitations, the IFFAS train might have required more carrier surface area to achieve complete nitrification consistently, even when the train was not overloaded.

\section{Specificities of the Integrated Fixed-Film Activated Sludge Process}

Attached Biomass. The measured attached biomass concentrations are shown in Figure 7 with the specific nitrification rate estimated for the carriers. They are compared with literature values, and their space distribution and time variations are discussed.

Biomass Concentration and Distribution. The attached biomass concentration in the first cell (2a) ranged from 15 to $35 \mathrm{~g}-\mathrm{TS} / \mathrm{m}^{2}$. This matches values measured by Maas et al. (2006) at the same plant in 2003 (20 to $25 \mathrm{~g}$-TS $/ \mathrm{m}^{2}$ ) and at other plants with floating carriers (Jones et al., 1999; Rutt et al., 2006; Von Munch et al., 2000). In the last cell (3b), concentrations ranged from 4 to $12 \mathrm{~g}-\mathrm{TS} / \mathrm{m}^{2}$, versus 12 to $15 \mathrm{~g}-\mathrm{TS} / \mathrm{m}^{2}$ found in 2003 by Maas et al. (2006). This is probably because the average organic loading was approximately double in 2003 (4600 kg-BOD $5 /$ d) compared with the 2005-2006 period.

The mass ratio between the attached biomass in the first and last cells (3.6, on average) appears high. This might result from the substrate concentration gradient that establishes between the first and last cell because of the plug-flow pattern. Onnis-Hayden et al. (2007) reported a ratio of only 1.6 between the attached biomass in the two cells at the Broomfield WWTP. However, the substrate gradient at this plant might be smoothed out, because the hydrodynamic pattern is closer to complete mix given the shape of the tanks and the aeration pattern (Johnson and Haegh, 2005). Visual observations also reveal that the carriers and biofilm at Lakeview have a strong rusty color in the first cell. Ferrous chloride is injected at the head of cell 2a (Figure 2). Thus, it can be assumed that iron precipitates make up a significant portion of the mass measured on the carriers in this cell. 


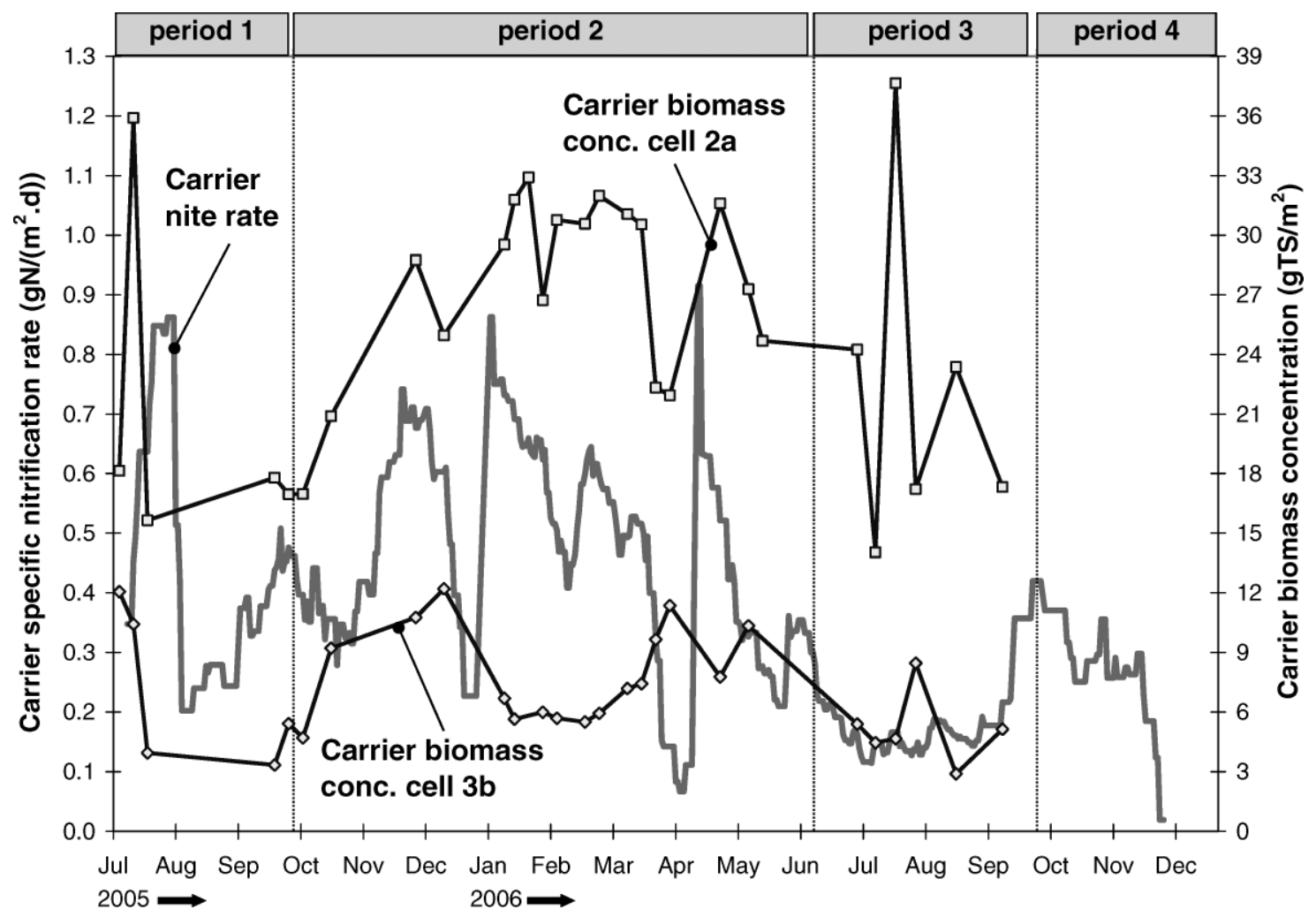

Figure 7-Attached biomass concentrations measured in the first and last IFFAS cell and calculated specific nitrification rates of the carriers (15-day averages over the four IFFAS cells).

A seasonal pattern can be identified on Figure 7, with a higher biofilm accumulation during the winter in the first cell (period 2). A similar trend has been observed at the Broomfield WWTP (Rutt et al., 2006). It is hypothesized that the biofilm is starved in the summer because of enhanced substrate removal by the mixed liquor. In addition, more active biofilm may accumulate on the carriers in the winter, because the endogenous decay rate decreases with temperature. This phenomenon is well-established for suspended biomass and leads to increased sludge production in the winter (Dold, 2007).

The two peaks above $35 \mathrm{~g}$-TS $/ \mathrm{m}^{2}$, which occurred in the summer, seem too sudden to have biological causes. While analytical errors cannot be excluded, physical explanations are also possible, such as deposits from iron dosing spikes or impaired carrier scouring.

Carrier Nitrification Rate. The range of the calculated nitrification rate $\left(0.2\right.$ to $\left.0.9 \mathrm{~g}-\mathrm{N} / \mathrm{m}^{2} \cdot \mathrm{d}\right)$ matches well with kinetics measured by batch assays at the same plant in 2003 and 2004 (Maas et al., 2006; Ross et al., 2004 ) and at other plants (Johnson and McQuarrie, 2002; Sen et al., 2005). The carrier nitrification rate follows a seasonal pattern, with highest values in the winter. It can be argued that this trend is induced by the rate calculation method: a higher fraction (80\%) of the total nitrification is attributed to the carriers when the suspended dSRT is below the critical SRT, which was mainly the case in the winter (period 2). However, it is noteworthy that the time variations of the calculated rate appear to correlate with the measured variations of biomass concentration. This validates the rate calculation method, to some extent, because the two variables were obtained independently. The carriers may have a stronger nitrifier population per surface area in the winter, as a result of the enhanced availability of substrate, because less ammonia is removed by the mixed liquor.

The observed biomass distribution and literature findings suggest that the nitrification rates are not uniform between cells. Maas et al. (2006) established that, in 2003, the rate was lowest in the first cell, as a result of the high organic loading. It would reach a peak in the 3rd cell, then decrease in the last cell, as a result of ammonia limitation. In this study, the available data only allow one to estimate one average nitrification rate for the four cells. However, the time variations of the calculated rate appear to correlate better with the biomass concentration in cell $2 \mathrm{a}$ than in cell $3 \mathrm{~b}$. This indirectly suggests that, unlike in 2003, the nitrification capacity was higher in the first cell than in the last cell, but nothing can be concluded about the two middle cells. This would match with the observations of Onnis-Hayden et al. (2007) at Broomfield WWTP, where the nitrification rate is highest in the first cell and substrate limited in the second one.

In conclusion, the range and seasonal variations of the concentration and nitrification rates of the attached biomass confirm literature results for similar IFFAS systems. The changes in space distribution of the biomass and of the nitrification capacity compared with 2003 (Maas et al., 2006) might be related to the decrease in loading by $50 \%$. However, the current results are preliminary, and additional investigations would be required to confirm the seasonal variations and spatial distribution of the attached biomass and its nitrifier population.

Lessons Learned from Full-Scale Operation. The specific operational requirements and issues encountered with the IFFAS train are exposed and discussed. Areas of concern include the IFFAS air requirements, management of the floating carriers (mixing, contain- 


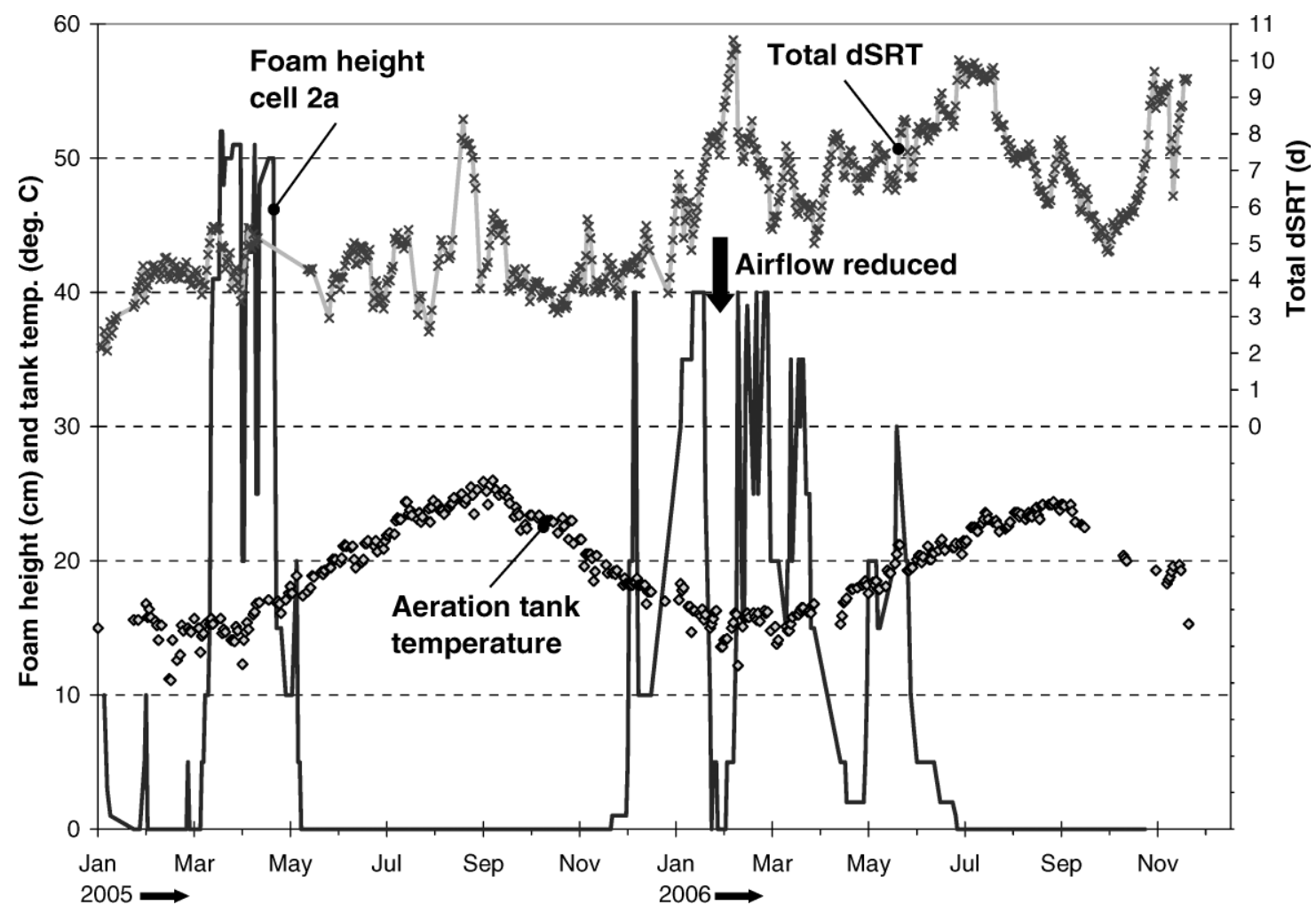

Figure 8-Foam heights in the first cell of the IFFAS train over 2 years.

ment, and displacement during tank maintenance), and seasonal foaming. To provide a complete overview of problems and solutions, the whole period since commissioning in October 2003 is considered. When possible, recommendations are formulated to incorporate improvements and corrections to the design stage.

Airflow Requirement. The median total airflow to the IFFAS train was 26\% higher than for the CAS train (Table 3), with a direct effect on operation cost. Even though the IFFAS may save some air with the anoxic selector, the last 2 passes required more air to maintain high dissolved oxygen concentrations $(>4.8 \mathrm{mg} / \mathrm{L}$ for $95 \%$ of the time in cell $3 \mathrm{~b}$ ), ensure carrier mixing, and feed the airknives. However, the air provision was not optimized on either demonstration train, so the quantitative difference should not be used as a general guideline for the IFFAS air requirement.

Carrier Mixing. Ideally, carriers should be mixed in a doubleroll pattern, with upwelling in the center and downwelling at the sides of the tank. Optimal mixing promotes detachment of excessive biomass (i.e., self-cleaning) and mass transfer between the liquid and the biofilm. Poor mixing can result in process limitations and, in more severe cases, hydraulic restrictions.

During the first months of operation, the carriers were frequently seen floating at the surface in a static "mat". This was possibly the result of the absence of lateral downwelling zones, as the problem was remedied in 2004 by removing the two outer rows of diffusers from each side of the IFFAS cells. After experiencing inadequate carrier mixing during IFFAS demonstration trials also, Yerrell et al. (2003) applied a similar principle by designing the aeration layout of the full-scale upgrade in a "T-shape". Full-floor coverage was provided near the screen, while coverage in the rest of the tank was limited to a centre aisle covering $43 \%$ of the tank width.
The formation of static mats is less frequent currently, but was still observed at least 3 times during the study period. It is attributed to airflow distribution imbalances. Airflow for passes 2 and 3 was distributed from one common header to 12 droplegs feeding the aeration grids and 4 droplegs feeding the airknives. Adjustments to either the total airflow or the flow to airknives can restrict the flow to one or several grids. In this case, valves are manually adjusted to redistribute the airflow, but this trial-and-error process can take a few days. Recommendations for future design include separate air headers for the air grids and the airknives, automated airflow distribution, and control valves with sufficient sensitivity to enable fine-tuning of airflow.

A more serious type of mixing disruption event is the accumulation of carriers behind the retention screens (bunching). High horizontal velocities in the tanks caused by peak influent flows might trigger bunching, but the peak design velocity of $51 \mathrm{~m} / \mathrm{h}$ was never exceeded during the study. The one bunching event reported during the study was related to low airflow to the airknives. Recommendations for design include minimizing hydraulic peaking, automating the airflow to the airknives using the influent flow as the control variable, and limiting the length-to-width ratio of the cells to 2, as recommended by Sen et al. (2005). At Lakeview, the cells are more elongated, with a ratio of 3.6.

Carrier Containment. Containment is a critical issue because escaping carriers can

(1) Affect the performance of the IFFAS process itself (loss of surface area);

(2) Accumulate in the clarifiers and severely disrupt the operation of associated equipment (clogging pipes and damaging pumps of WAS, RAS, and scum lines); 
(3) Migrate to downstream processes, such as BTP; and

(4) Be released into receiving waters.

During the first few months of operation, carriers escaped from cell $3 b$ following a bunching event and accumulated in the final clarifier. They either passed over the screen or they were deformed and passed through the screen. Airflows to airknives were adjusted, and screens were extended with the installation of horizontal screens at their top edge (Ross et al., 2004). In early 2005 and again in late 2006, carriers escaped upstream into the primary influent channel and contaminated the conventional trains of plant 1 . Upstream migration occurs during periods of low or no flow typically required for maintenance or repair. As a result of a hydrostatic pressure difference, the IFFAS train drains partially backwards into the primary effluent channel. Because there is no screen at the front end of cell 2a (Figure 2), its carriers are drawn upstream with the flow. A fixed sluice gate was installed between passes 1 and 2 to increase the horizontal velocity locally at the front of cell $2 \mathrm{a}$, in case of low flow. When the flow is shut down completely, the IFFAS feed gate is closed immediately, to prevent backflow. Adding a screen at the front end of the IFFAS section is not feasible, because it would likely experience biological fouling, as there would be no scouring by carriers on its upstream side. If the whole plant was upgraded to IFFAS, the presence of screens in all trains would prevent this type of carrier dissemination.

Carrier Management During Tank Maintenance. Taking a train down is occasionally necessary (e.g., for diffuser maintenance). In 2004, the IFFAS train needed to be drained. The carriers were left in place, but the weight of the biofilm-covered carriers cracked the air lines of the aeration grid. To repair the air lines, the carriers needed to be removed also, which was technically challenging. They were eventually resuspended in water, pumped with an airlift pump, and stored on the ground, because no empty tank was available. The air lines were repaired and reinforced by increasing the diameter and reducing the spacing of the pipe supports.

If IFFAS cells can be isolated and drained in a sequence, then it is possible to transfer the carriers from the cell to be drained to a second cell for temporary storage. An alternative is to have a dedicated tank available for carrier storage. This is costly, in terms of money and space.

Seasonal Foaming. All of Lakeview's treatment trains experience periodic foaming events, which may be the result of influent characteristics. However, the IFFAS train has more frequent and severe foaming events, suggesting that it has design and/or operational features that make it more susceptible to foaming than conventional trains.

Foam thickness records from January 2005 to December 2006 are displayed in Figure 8, with temperature and the dynamic total SRT (suspended + attached biomass). The foam is light to dark brown, with coverage varying from scattered patches to being complete. At times, the foam can occupy all the freeboard $(40 \mathrm{~cm})$ and spill onto walkways. Filamentous foam-causing microorganisms, mainly Microthrix parvicella and on one occasion nocardioform actinomycetes, have been identified by microscope observations. High SRTs ( $>6$ to 9 days) and grease-rich influent are known conditions promoting growth of both filaments. $M$. parvicella causes foaming at cold temperatures $\left(<18^{\circ} \mathrm{C}\right)$ and low loading rates (Knoop and Kunst, 1998; Madoni and Davoli, 1997; Mamais et al., 1998; Noutsopoulos et al., 2006; Xie et al., 2007), while nocardioforms thrive at warmer temperatures (Madoni and Davoli, 1997; Sen et al.,
2005). Figure 8 shows that foaming stops as soon as the temperature increases past $19^{\circ} \mathrm{C}$ (May to June). This supports the case for $M$. parvicella being responsible for foam formation. However, foaming occurred at total dSRTs as low as 4 to 5 days in the winter of 2005 (suspended dSRT 2 to 3 days), which contradicts the literature. In this case, foaming events may be better correlated with variations of the SRT rather than with its absolute value. On several occasions, it seems that a sharp increase in SRT triggered foam formation (March and April 2005 and January 2006), while a sharp reduction in SRT through enhanced wastage helped to clear the foam (March 2005 and 2006). Another control action that succeeded at reducing the foam was to reduce the airflow to the IFFAS cells (January 2006). This action is somewhat risky, as it may result in poor carrier mixing.

In biological nutrient removal (BNR) systems, reactor configuration plays a significant role in $M$. parvicella proliferation. One key point is to provide a zone with a high loading, where floc formers are at advantage for substrate adsorption over filamentous organisms. This condition is provided by either a selector or a PFT configuration. Interestingly, the IFFAS train combines both features. However Madoni and Davoli (1993 and 1997) found that anaerobic or anoxic selectors are inefficient for the control of $M$. parvicella and recommend aerobic selectors with very high loading. A mere PFT configuration is another option (Mamais et al., 1998; Noutsopoulos et al., 2002). Thus, based on the literature, the anoxic selector might be detrimental to the control of M. parvicella in the IFFAS train, while the conventional trains are better protected against this filament, because their first pass is completely aerated. Nevertheless, the anoxic selector may still provide protection against other types of filamentous organisms.

In conclusion, as other BNR processes operating at reduced loadings, the IFFAS process may be more at risk for foaming, even though it has been impossible to pinpoint the exact cause of foaming from this case study. Based on the literature review, specific design recommendations to protect against foam development would include a plug-flow configuration, with the flexibility of managing the head zone as either an aerated or an unaerated selector, to adapt to the type of filamentous organism involved. When unaerated, it is important that the selector be strictly anoxic or strictly anaerobic, without any oxygen input from RAS or influent, according to the latest findings from Martins et al. (2004).

Design features to manage foam once it has accumulated could include a higher freeboard and a mechanism to collect and waste the foam from the aeration tank. This is admittedly not easy in the presence of carriers.

\section{Conclusion}

During the 18 months of this study, the IFFAS demonstration train and the CAS reference train were operated under similar loadings and suspended biomass inventories. Thus, the effects of biofilm carrier addition could be evaluated by comparing the two trains directly. Both trains were overloaded for the first 7 months of the study, as a result of high flows and sidestreams from BTP. The average organic and nitrogen load gradually decreased for the following 11 months, but peaks still occurred.

The IFFAS had 50\% more biomass compared with the CAS train, which granted a lower F: $\mathrm{M}_{\mathrm{v}}$ and a higher total SRT. The attached biomass was not distributed evenly across the four cells, because $60 \%$ was harbored in the first cell. The biomass concentration and nitrification activity on the carriers followed a seasonal pattern, with 
highest values in the winter. It is thought that more organic and nitrogen substrate was available for the biofilm in the winter, as a result of reduced removal by the mixed liquor.

Both trains had excellent removal performance for suspended solids and organic matter. The CAS train had partial nitrification capacity most of the time, but only met the ammonia objective of $5 \mathrm{mg}-\mathrm{N} / \mathrm{L}$ for $32 \%$ of the time. Once the TKN loading remained mostly below the design limit, the ammonia compliance increased to $47 \%$. The main cause of poor nitrification was a low SRT (median 3.6 days). In the summer, the SRT was sufficient to maintain a stable nitrifier population, but it was insufficient to handle loading peaks. During the winter, the CAS train was operating close to the critical value for nitrifiers, and its ability to nitrify was unstable and, at times, lost completely.

The IFFAS train met the objective of $5 \mathrm{mg}-\mathrm{N} / \mathrm{L}$ for $58 \%$ of the time and up to $67 \%$ of the time once the TKN loading remained mostly below the design limit. The IFFAS nitrification performance was significantly improved compared with the CAS in winter, with a roughly doubled nitrification rate. When the suspended SRT was limiting, the carriers had a positive contribution, by maintaining a fixed nitrifier population. In the summer, the IFFAS nitrification performance was similar to the conventional train. When the suspended SRT was not limiting, the benefit of the carriers was marginal. Factors preventing consistent complete nitrification in the IFFAS train may have included dissolved oxygen limitation in the first cell(s) and residual alkalinity. The carrier surface area may have been too low for these circumstances.

Despite the good quality and large amounts of information extracted from this full-scale data set, many of the conclusions would need to be confirmed by laboratory-scale batch tests (e.g., nitrification kinetics of the suspended and the attached biomass) and enhanced characterization of the attached biomass (e.g., spatial profiles and organic and inorganic composition) and suspended biomass (microscope observations, floc properties, and filamentous species identification).

The improved performance of the IFFAS train was moderated by the cost of the increased airflow requirement and by recurring operational problems that have been encountered since startup. They include the following, in order of increasing inconvenience: impaired carrier mixing, seasonal foaming (winter), challenging carrier transfer and storage during tank maintenance, and occasional carrier escape (downstream and upstream). It is anticipated that the IFFAS technology was not directly responsible for the winter foaming. It was caused by the filamentous bacteria $M$. parvicella, which is typical of conditions found in BNR systems. An anoxic selector is ineffective against this species and ironically may have even contributed to its development.

This demonstration project has been a successful learning experience in identifying and correcting both process and operational issues, which may not have arisen at pilot scale. Problems were dealt with as they came up, and, as this type of technology becomes more mature, design modifications will ease and improve the operation.

\section{Credits}

The IFFAS demonstration project was initiated by the Region of Peel (Brampton, Ontario, Canada) and designed by KMK Consultants Ltd. (Brampton, Ontario, Canada) (Deborah Ross and colleagues). The biofilm carriers were provided by Hydroxyl Systems Inc. (Victoria, British Columbia, Canada). The Lakeview WWTP is operated by the Ontario Clean Water Agency (Toronto,
Ontario, Canada) (Dave Neely and colleagues). This study was funded by the Region of Peel, Environment Canada, and the Ontario Ministry of the Environment.

Yves Comeau (Ecole Polytechnique de Montréal, Quebec, Canada) is acknowledged for his kind and highly useful advice for data presentation and writing of this paper.

Submitted for publication April 7, 2008; revised manuscript submitted July 9, 2008; accepted for publication July 21, 2008.

The deadline to submit Discussions of this paper is June 15, 2009.

\section{References}

American Public Health Association; American Water Works Association; Water Environment Federation (2005) Standards Methods for the Examination of Water and Wastewater, 21st ed.; American Public Health Association: Washington, D.C.

Barker, P. S.; Dold, P. (1995) COD and Nitrogen Mass Balances in Activated Sludge Systems. Water Res., 29 (2), 633-643.

Dold, P. (2007) Quantifying Sludge Production in Municipal Treatment Plants. Proceedings of the 80th Annual Water Environment Federation Technical Exhibition and Conference, San Diego, California, Oct. 1317; Water Environment Federation: Alexandria, Virginia.

Dold, P.; Stensel, H. D.; Ke, R.; Jones, R. M.; Bye, C.; Melcer, H. (2002) Importance of Decay Rate in Assessing Nitrification Kinetics. Proceedings of the 75th Annual Water Environment Federation Technical Exhibition and Conference, Chicago, Illinois, Sept. 28Oct. 2; Water Environment Federation: Alexandria, Virginia.

Federico, J.; Richtarik, S.; Gilligan, T. (2002) IFAS System Demonstration of Cold Temperature Nitrogen Removal. Proceedings of the 75th Annual Water Environment Federation Technical Exhibition and Conference, Chicago, Illinois, Sept. 28-Oct. 2; Water Environment Federation: Alexandria, Virginia.

Grulois, P.; Famel, J.-C.; Hangouet, J.-P.; Fayoux, C. (1996) Rien ne se perd, rien ne se crée, tout se transforme...en boues! (Nothing Gets Lost, Nothings Gets Created, Everything Gets Transformed. . Into Sludge!) L'eau, l'industrie, les nuisances, (195), 42-46 (in French).

Hubbell, S. B.; Pehrson, R. L.; Schuler, A. (2006) Eight Years of Successful Cold Weather Nitrification with Integrated Fixed-Film/Activated Sludge. Proceedings of the 79th Annual Water Environment Federation Technical Exhibition and Conference, Dallas, Texas, Oct. 21-25; Water Environment Federation: Alexandria, Virginia.

Johnson, C. H.; Haegh, M. (2005) Increasing BNR Capacity in Activated Sludge Systems by Use of Suspended Carrier IFAS TechnologyExample from a Full Scale Installation at Broomfield BWRF in Colorado, USA. Proceedings of the IWA Specialist Conference Nutrient Management in Wastewater Treatment Processes and Recycle Streams, Krakow, Poland, Sept. 18-21; IWA: London, United Kingdom.

Johnson, T. L.; McQuarrie, J. P. (2002) IFAS BNR Full-Scale Design and Performance Challenges. Proceedings of the 75th Annual Annual Water Environment Federation Technical Exhibition and Conference, Chicago, Illinois, Sept. 28-Oct. 2; Water Environment Federation: Alexandria, Virginia.

Jones, R. M.; Lambert, R.; Manoharan, R.; Crane, R.; Campbell, H. (1999) Demonstration of an Integrated Fixed Film Activated Sludge (IFAS) System for Enhanced Nitrification Using a New Free Moving Media. Proceedings of the Annual Technical Symposium of the Water Environment Association of Ontario, Toronto, Ontario, Canada, April 12-13; Water Environment Association of Ontario: Milton, Ontario, Canada.

Knoop, S.; Kunst, S. (1998) Influence of Temperature and Sludge Loading on Activated Sludge Settling, Especially on Microthrix parvicella. Water Sci. Technol., 37 (4-5), 27-35.

Maas, C. L. A.; Parker, W. J.; Legge, R. L. (2006) Process Observations from Start-Up of an Integrated Fixed-Film Activated Sludge Process. 
Proceedings of the 35th Annual WEAO Technical Symposium and OPCEA Exhibition, Toronto, Ontario, Canada, April 9-11; Water Environment Association of Ontario: Milton, Ontario, Canada.

Madoni, P.; Davoli, D. (1993) Control of Microthrix parvicella Growth in Activated Sludge. FEMS Microbiol. Ecol., 12 (4), 277-283.

Madoni, P.; Davoli, D. (1997) Testing the Control of Filamentous Microorganisms Responsible for Foaming in a Full-Scale ActivatedSludge Plant Running with Initial Aerobic or Anoxic Contact Zones. Bioresour. Technol., 60 (1), 43-49.

Mamais, D.; Andreadakis, A.; Noutsopoulos, C.; Kalergis, C. (1998) Causes of, and Control Strategies for, Microthrix parvicella Bulking and Foaming in Nutrient Removal Activated Sludge Systems. Water Sci. Technol., 37 (4-5), 9-17.

Martins, A. M. P.; Heijnen, J. J.; van Loosdrecht, M. C. M. (2004) Bulking Sludge in Biological Nutrient Removal Systems. Biotechnol. Bioeng., 86 (2), 125-135.

Masterson, T.; Federico, J.; Hedman, G.; Duerr, S. (2004) Upgrading for Total Nitrogen Removal with a Porous Media IFAS System. Proceedings of the 77th Annual Water Environment Federation Technical Exhibition and Conference, New Orleans, Louisiana, Oct. 2-6; Water Environment Federation: Alexandria, Virginia.

McQuarrie, J. P.; Rutt, K.; Seda, J.; Haegh, M. (2004) Observations from the First Year of Full-Scale Operation-The IFAS/BNR Process at the Broomfield Wastewater Reclamation Facility, Broomfield, CO. Proceedings of the 77th Annual Water Environment Federation Technical Exhibition and Conference, New Orleans, Louisiana, Oct. 2-6; Water Environment Federation: Alexandria, Virginia.

Metcalf and Eddy (2003) Wastewater Engineering, Treatment and Reuse, 4th ed.; McGraw-Hill: New York.

Noutsopoulos, C.; Mamais, D.; Andreadakis, A. (2006) Effect of Solids Retention Time on Microthrix parvicella Growth. Water SA, 32 (3), 315-321.

Noutsopoulos, C.; Mamais, D.; Andreadakis, A. (2002) The Effect of Reactor Configuration and Operational Mode on Microthrix Parvicella Bulking and Foaming in Nutrient Removal Activated Sludge Systems. Water Sci. Technol., 46 (1-2), 61-64.

Onnis-Hayden, A.; Dair, D.; Johnson, C. H.; Schramm, A.; Gu, A. Z. (2007) Kinetics and Nitrifying Populations in Nitrogen Removal Processes at a Full-Scale Integrated Fixed-Film Activated Sludge (IFAS) Plant. Proceedings of the 80th Annual Water Environment Federation Technical Exhibition and Conference, San Diego, California, Oct. 13-17; Water Environment Federation: Alexandria, Virginia.

Psaltakis, E. P.; Liubicich, J.; Pitt, P.; Antonio, P.; Posada, S.; Zabinski, A. J.; Lauro, T. J. (2003) Demonstration of Integrated Fixed Film Activated Sludge Process for BNR at the Mamaroneck WWTP. Proceedings of the 76th Annual Water Environment Federation
Technical Exposition and Conference, Los Angeles, California, Oct. 11-15; Water Environment Federation: Alexandria, Virginia.

Ross, D.; Fernandes, W. (2002) Innovative Integrated Fixed-Film/Activated Sludge Retrofit Could Save Millions. Environ. Sci. Eng., November.

Ross, D.; Fernandes, W.; Briggs, T.; Kirn, N.; Booth, G.; Neely, D.; Welp, J. (2004) Integrated Fixed Film Activated Sludge (IFAS) at the Lakeview WWTP. The Real Implementation Issues. Proceedings of the 77 th Annual Water Environment Federation Technical Exhibition and Conference, New Orleans, Louisiana, Oct. 2-6; Water Environment Federation: Alexandria, Virginia.

Rutt, K.; Seda, J.; Johnson, C. H. (2006) Two Year Case Study Of Integrated Fixed Film Activated Sludge (IFAS) at Broomfield, CO WWTP. Proceedings of the 79th Annual Water Environment Federation Technical Exhibition and Conference, Dallas, Texas, Oct. 21-25; Water Environment Federation: Alexandria, Virginia.

Sen, D.; Copithorn, R. R.; Randall, C. W. (2005) Municipal IFAS and MBBR Systems as Measured in Terms of Minimum Hydraulic Retention Times and Mixed Liquor MCRT. Proceedings of the 78th Annual Water Environment Federation Technical Exhibition and Conference, Washington, D.C., Oct. 29-Nov. 2; Water Environment Federation: Alexandria, Virginia.

Stricker, A. E.; Lishman, L.; Barrie, A. (in press) Effects of Fluctuating Iron Dosage on Nitrification in Integrated Fixed Film and Conventional Activated Sludge Processes. Water Environ. Res.

Takacs, I.; Patry, G. G. (2004) The Dynamic Solids Residence Time. Proceedings of the 3rd World Water Congress, Melbourne, Australia, April 7-12; IWA: London, United Kingdom.

Von Munch, E.; Barr, K.; Watts, S.; Keller, J. (2000) Suspended Carrier Technology Allows Upgrading High-Rate Activated Sludge Plants for Nitrogen Removal Via Process Intensification. Water Sci. Technol., $41(4-5), 5-12$.

Xie, B.; Dai, X. C.; Xu, Y. T. (2007) Cause and Pre-Alarm Control of Bulking and Foaming by Microthrix Parvicella-A Case Study in Triple Oxidation Ditch at a Wastewater Treatment Plant. J. Hazard. Mater, 143 (1-2), 184-191.

Yerrell, K.; Gobbie, M.; Dold, P.; Jones, R. M.; Sickerdick, L. (2001) FullScale Demonstration of a Free-Moving Media IFAS Process for Enhancing Nitrification Performance. Proceedings of the 74th Annual Water Environment Federation Technical Exposition and Conference, Atlanta, Georgia, Oct. 13-17; Water Environment Federation: Alexandria, Virginia.

Yerrell, K.; Maclaren, D.; Dold, P.; Jones, R. M.; Sickerdick, L. (2003) Integrated Fixed Film Activated Sludge IFAS-Full Scale Trial to Operating Plants. Proceedings of the OzWater 2003 Convention, Perth, Australia, April 6-10; Australian Water Association: St. Leonards, NSW, Australia. 